УДК 581.135.51:582.924

\title{
ЗАВИСИМОСТЬ СОСТАВА ЭФИРНОГО МАСЛА MONARDA DIDYMA L. (LAMIACEAE) ОТ ВОЗРАСТА РАСТЕНИЙ И ХАРАКТЕРА СЫРЬЯ
}

\author{
() М.А. Мяделеи ${ }^{I^{*}}$, Д.В. Домрачев ${ }^{2}$, А.Н. Крикливая ${ }^{I}$, Г.И. Высочина ${ }^{I}$ \\ ${ }^{1}$ Центральный сибирский ботанический сад СО РАН, ул. Золотодолинская, \\ 101, Новосибирск, 630090 (Россия), e-mail: MarinaMyadelets@yandex.ru \\ ${ }^{2}$ Новосибирский институт органической химии им. Н.Н. Ворожцова СО РАН, \\ пр. акад. Лаврентьева, 9, Новосибирск, 630090 (Россия), e-mail: dmitry@nioch.nsu.ru
}

Методом хромато-масс-спектрометрии исследован химический состав эфирного масла Monarda didyma L. (Lamiaceae), культивируемой в лесостепной зоне Омской области. Для получения эфирного масла использовали свежесобранное и высушенное сырье растений второго и третьего годов жизни. Отмечаются отличия в составе полученного масла. Всего обнаружено более 50 компонентов, из них идентифицировано 37 соединений. Основными компонентами являются тимол $(64,9 \%)$, метиловый эфир тимола $(7,6)$, nара-цимол $(9,5), \gamma$-терпинен $(3,6)$, окт-1-ен-3-ол $(2,9)$, $\alpha$-терпинен $(2,3)$ и карвакрол $(1,2 \%)$.

Ключевые слова: Monarda didyma L., эфирное масло, хромато-масс-спектрометрия.

\section{Введение}

Одним из перспективных родов, содержащих ценное по компонентному составу эфирное масло и обладающих высокой экологической пластичностью, является североамериканский род Monarda L. (монарда). Во многих странах Европы и Америки монарда введена в культуру как декоративное, пряноароматическое и лекарственное растение [1,2]. В России встречается только в условиях культуры в европейской части страны, на Урале и в Сибири [3].

Использование монарды в народной медицине имеет длительную историю [4]. Лекарственные свойства видов этого рода в значительной степени определяются содержанием эфирных масел. Основной компонент эфирного масла растений рода Monarda L. - тимол обладает сильной антибактериальной и фунгистатической активностью [5]. Как перспективное эфиромасличное растение Monarda изучалась в Никитском и Центральном сибирском ботанических садах, Всероссийском НИИ лекарственных и ароматических растений, Всероссийском НИИ растениеводства им. Н.И. Вавилова. Опубликованные на сегодняшний день работы по анализу химического состава эфирных масел монарды касаются растений, возделываемых на южном бе-

Мяделеи Марина Александровна - научный сотрудник лаборатории фитохимии, кандидат биологических наук, тел.: (383) 339-98-14,

e-mail: MarinaMyadelets@yandex.ru

Домрачев Дмитрий Васильевич - инженер 1-й категории лаборатории терпеновых соединений, тел.: (383) 330-98-55, e-mail: dmitry@ nioch.nsu.ru Крикливая Анастасия Николаевна - аспирант лаборатории интродукции лекарственных и пряноароматических растений, тел./факс (3812) 65-10-72, e-mail:shan368@mail.ru

Высочина Галина Ивановна - заведующая

лабораторией фитохимии, доктор биологических наук, профессор, тел.: (383) 339-98-10,

e-mail: vysochina_galina@mail.ru регу Крыма, Северном Кавказе, в Московской и Ленинградской областях и Сибирском регионе [6].

Учитывая хозяйственно важные показатели (морозоустойчивость, эфиромасличность, урожайность, способность к семенному и вегетативному размножению) видов этого рода считаем, что одним из перспективных видов для возделывания на территории России является Monarda didyma L. (монарда двойчатая) [5, 7].

В работе В.В. Николаевского с соавторами [8] показано, что эфирное масло $M$. didyma обладает наибольшей антимикробной активностью из всех изученных эфирных масел, превосходя известные

\footnotetext{
* Автор, с которым следует вести переписку.
} 
масла эвкалипта, чайного дерева, чабреца. Надземная часть $M$. didyma содержит до 2,4\% (в расчете на сухой вес) эфирного масла. В составе масла идентифицировано 26 компонентов. Основными являются тимол $(65,9 \%)$, карвакрол $(10,7), \gamma$-терпинен $(6,3), 1$-октен-3-ол $(3,5)$, п-цимол $(2,8), \alpha$-терпинен $(1,5), \beta$-мирцен $(1,2 \%)[7]$.

Известно, что род Монарда характеризуется сильным полихимизмом и широким диапазоном содержания эфирного масла в сырье [9]. Есть данные, показывающие существенные различия в содержании эфирного масла в сырье образцов M. didyma различного происхождения [10].

Цель данной работы - изучение компонентного состава эфирного масла (ЭМ) растений M. didyma при интродукции в лесостепной зоне Омской области, сравнение его с маслом растений, выращенных в других регионах России и исследование изменчивости компонентного состава ЭМ в зависимости от возраста растений и характера сырья.

\section{Материальи и методы}

Исследуемый материал - сырье M. didyma - собирали на интродукционном участке Ботанического сада ФГБОУ ВПО ОмГАУ им. П.А. Столыпина. Учитывая данные других исследований, сбор сырья производился в фазе цветения, когда максимальная урожайность сочетается с высоким содержанием эфирного масла [5]. Обработка растений фиторегуляторами не проводилась. Исследовали образцы растений второго и третьего годов жизни, полученные из семян репродукции $M$. didyma указанного интродукционного участка. Эфирное масло получали по методу Гинзберга из свежего и воздушно-сухого сырья [11]. Исследовались образцы масел, полученные из соцветий, стеблей и листьев, а также из всей облиственной надземной части растения. Выход эфирного масла определяли в процентах от массы абсолютно-сухого сырья.

Хромато-масс-спектрометрический анализ проводили на газовом хроматографе Hewlett-Packard 5890/II с квадрупольным масс-спектрометром (HP MSD 5971) в качестве детектора. Использовалась 30метровая кварцевая колонка НР-5 (сополимер 5\%-дифенил-95\%-диметилсилоксана) с внутренним диаметром 0,25 мм и толщиной пленки неподвижной фазы 0,25 мкм. Содержание компонентов вычислялось по площадям газо-хроматографических пиков без использования корректирующих коэффициентов. Качественный анализ основан на сравнении индексов удерживания и полных масс спектров с атласом спектров [12].

\section{Результаты и их обсуждение}

Выход эфирного масла в исследуемых образцах составил 0,92-2,11\%. Отличий в содержании эфирного масла растений второго и третьего годов жизни нами отмечено не было. Наибольшее его содержание выявлено в листьях и стеблях $(2,11 \%)$, наименьшее в соцветиях $(0,92 \%)$, из всей надземной части получено 1,26\%. Следовательно, содержание эфирного масла не уступает таковому в традиционных районах выращивания M. didyma $[13,14]$. Кроме того, количество эфирного масла будет определяться долей листьев и соцветий в сырье [5]. В культуре M. didyma может сильно поражаться мучнистой росой (Erysiphe monardae, Golovinomyces biocellatus), об этом свидетельствуют данные других исследователей [5, 15 $\square]$ и наши наблюдения. Частичное поражение мучнистой росой встречается в фазе массового цветения растения, но большей частью болезнь проявляется при понижении среднесуточной температуры и при повышенной влажности. Учитывая данные о влиянии мучнисто-росяного гриба Golovinomyces biocellatus на выход и компонентный состав эфирного масла Monarda fistulosa (сорт 'Премьера') [15], можно предположить влияние данного фактора на содержание и состав масла M. didyma.

Хромато-масс-спектрометрический анализ позволил установить в эфирном масле M. didyma 1-го и 2-го годов цветения наличие более 50 компонентов. В исследуемых образцах идентифицировано от 30 до 37 компонентов (табл.), что существенно дополнило имеющиеся литературные данные о компонентном составе исследуемого вида растений. Основными компонентами являются тимол (64,9\%), метиловый эфир тимола $(7,6)$, n-цимол $(9,5), \gamma$-терпинен $(3,6)$, окт-1-ен-3-ол $(2,9), \alpha$-терпинен $(2,3)$ и карвакрол $(1,2 \%)$. Полученные данные сопоставимы с составом эфирных масел $M$. didyma, выращенной на территории Новосибирской области (окрестность Академгородка) [7]. Отличия наблюдаются в более низком содержании карвакрола в исследуемых нами образцах. Полученные результаты подтверждают данные других исследователей о том, что многие эфиромасличные культуры обладают довольно стабильным компонентным составом при возделывании в разных почвенно-климатических зонах [16]. 
Состав эфирного масла Monarda didyma

\begin{tabular}{|c|c|c|c|c|c|c|c|c|}
\hline \multirow{4}{*}{ R.I. } & \multirow{4}{*}{ Компоненты } & \multicolumn{7}{|c|}{ Содержание компонентов в процентах от цельного масла } \\
\hline & & \multicolumn{4}{|c|}{ 1-й год цветения } & \multicolumn{3}{|c|}{ 2-й год цветения } \\
\hline & & соцветия & $\begin{array}{l}\text { стебли, } \\
\text { листья }\end{array}$ & соцветия & $\begin{array}{c}\text { стебли, } \\
\text { листья }\end{array}$ & соцветия & $\begin{array}{l}\text { стебли, } \\
\text { листья }\end{array}$ & $\begin{array}{c}\text { стебли, } \\
\text { листья, } \\
\text { соцветия }\end{array}$ \\
\hline & & \multicolumn{2}{|c|}{ свежее } & \multicolumn{2}{|c|}{ cyxoe } & \multicolumn{3}{|c|}{ свежее сырье } \\
\hline 926 & 3-туйен & 0,1 & 0,2 & 1,4 & 0,6 & 0,6 & 0,8 & 0,7 \\
\hline 932 & $\alpha$-пинен & - & + & 0,4 & 0,2 & 0,2 & 0,2 & 0,2 \\
\hline 947 & Камфен & - & - & 0,1 & - & + & + & + \\
\hline 973 & Сабинен & + & - & 0,1 & + & - & - & - \\
\hline 975 & $\beta$-пинен & + & - & 0,1 & 0,1 & 0,1 & 0,1 & 0,1 \\
\hline 979 & Окт-1-ен-3-ол & 1,2 & 2,2 & 1,8 & 2,3 & 2,3 & 2,6 & 2,9 \\
\hline 987 & Октан-3-он & + & 0,1 & 0,1 & 0,1 & 0,1 & 0,1 & 0,1 \\
\hline 992 & $\beta$-мирцен & 0,7 & 0,6 & 0,2 & 0,8 & 0,7 & 1,1 & - \\
\hline 996 & Октан-3-ол & - & + & - & 0,1 & 0,1 & - & 0,1 \\
\hline 1004 & $\alpha$-феландрен & 0,2 & 0,1 & 0,1 & 0,2 & 0,2 & 0,3 & 0,2 \\
\hline 1010 & 3-карен & 0,3 & 0,1 & 0,1 & 0,1 & 0,1 & 0,1 & 0,1 \\
\hline 1016 & $\alpha$-терпинен & 1,6 & 1,4 & 2,9 & 2,1 & 2,0 & 2,6 & 2,3 \\
\hline 1024 & пара-цимол & 4,9 & 4,2 & 18,7 & 7,8 & 13,7 & 7,7 & 9,5 \\
\hline 1028 & Лимонен & 0,6 & 0,4 & 1,2 & 0,8 & 0,6 & 0,6 & 0,6 \\
\hline 1030 & 1,8 -цинеол & 0,1 & - & 0,3 & - & - & - & - \\
\hline 1048 & транс-б-оцимен & + & + & - & - & - & - & - \\
\hline 1058 & $\gamma$-терпинен & 8,3 & 5,4 & 0,1 & 4,4 & 2,7 & 4,4 & 3,6 \\
\hline 1066 & транс-сабиненгидрат & 0,7 & 0,7 & 0,4 & 0,3 & 0,3 & 0,6 & 0,3 \\
\hline 1080 & Нон-1-ен-3-ол & - & + & - & + & + & - & - \\
\hline 1088 & Терпинолен & 0,1 & 0,1 & 0,1 & 0,1 & 0,1 & 0,1 & 0,1 \\
\hline 1097 & циис-сабиненгидрат & 0,1 & 0,1 & 0,1 & 0,1 & 0,2 & 0,1 & 0,1 \\
\hline 1100 & Линалоол & - & 0,1 & 0,1 & 0,1 & - & - & - \\
\hline 1105 & Нонанал & - & 0,1 & - & - & - & - & - \\
\hline 1113 & Окт-1-ен-3-ол ацетат & - & - & - & - & 0,1 & + & + \\
\hline 1140 & иис-пара-мент-2-ен-1-ол & + & - & - & + & - & - & - \\
\hline 1165 & Борнеол & 0,1 & 0,1 & 0,2 & 0,1 & 0,1 & 0,1 & 0,1 \\
\hline 1177 & Терпинен-4-ол & 0,9 & 0,7 & 1,2 & 0,7 & 1,0 & 0,4 & 0,9 \\
\hline 1184 & мета-цимен-8-ол & - & - & - & 0,1 & - & - & - \\
\hline 1186 & пара-цимен-8-ол & - & - & - & - & 0,1 & - & + \\
\hline 1190 & $\alpha$-терпинеол & 0,2 & 0,2 & 0,2 & 0,2 & 0,1 & 0,1 & 0,1 \\
\hline 1236 & Метиловый эфир тимола & 3,4 & 7,4 & 3,8 & 7,1 & 6,8 & 6,8 & 7,6 \\
\hline 1245 & Метиловый эфир карвакрола & - & 0,1 & - & 0,1 & 0,1 & 0,1 & 0,1 \\
\hline 1292 & Тимол & 65,1 & 66,4 & 55,4 & 64,4 & 59,5 & 67,2 & 64,9 \\
\hline 1303 & Карвакрол & 6,4 & 3,3 & 4,9 & 2,7 & 1,5 & 1,0 & 1,2 \\
\hline 1305 & изо-аскаридол & 0,4 & - & - & - & - & - & - \\
\hline 1351 & $\alpha$-кубебен & - & 0,1 & - & - & - & - & - \\
\hline 1359 & Эвгенол & + & - & - & - & + & - & + \\
\hline 1376 & $\alpha$-копаен & 0,1 & - & 0,1 & 0,1 & 0,1 & + & + \\
\hline 1385 & $\beta$-бурбонен & + & 0,1 & - & 0,1 & - & - & - \\
\hline 1393 & $\beta$-элемен & + & 0,1 & - & - & 0,1 & + & + \\
\hline 1420 & Кариофилен & 0,3 & 0,3 & 0,2 & 0,2 & - & - & - \\
\hline 1430 & $\beta$-копаен & + & 0,1 & - & + & + & - & - \\
\hline 1463 & 9-эnи-изокариофиллен & - & - & - & - & 0,1 & 0,1 & 0,1 \\
\hline 1480 & $\gamma$-муролен & - & - & 0,1 & - & 0,1 & 0,1 & 0,1 \\
\hline 1482 & Гермакрен D & 1,0 & 1,2 & 0,6 & 0,6 & 0,4 & 0,5 & 0,2 \\
\hline 1488 & $\beta$-селинен & - & - & - & - & 0,1 & - & 0,1 \\
\hline 1510 & $(E, E)$-а-фарнезен & - & 0,2 & - & - & - & - & - \\
\hline 1518 & Z- $\gamma$-бизаболен & 0,1 & - & - & 0,1 & - & - & - \\
\hline 1515 & $\gamma$-кадинен & 0,1 & 0,1 & 0,1 & 0,1 & 0,1 & - & 0,1 \\
\hline 1525 & $\delta$-кадинен & 0,2 & 0,2 & 0,2 & 0,2 & 0,2 & 0,1 & 0,2 \\
\hline 1644 & Т-муролол & + & 0,4 & - & 0,3 & - & - & - \\
\hline
\end{tabular}

Примечание. “+” - содержание соответствующего компонента не превышает 0,05\%. 
Сопоставление состава образцов эфирных масел $M$. didyma, полученных из свежего и высушенного сырья, показывает, что компонентный состав при высушивании сырья не изменился. Изменения коснулись содержания некоторых компонентов. Так, при высушивании сырья увеличивается содержание 3-туйена (с 0,1 до $1,4 \%$ в соцветиях и с 0,2 до $0,6 \%$ в стеблях и листьях), $\alpha$-терпинена (с 1,6 до 2,9\% в соцветиях и с 1,4 до $2,1 \%$ в стеблях и листьях), пара-цимола (с 4,9 до $18,7 \%$ в соцветиях и с 4,2 до 7,8\% в стеблях и листьях), уменьшается содержание $\gamma$-терпинена (с 8,3 до 0,1\% в соцветиях и с 5,4 до 4,4\% в стеблях и листьях), тимола (с 65,1 до 55,4\% в соцветиях и с 66,4 до 64,4\% в стеблях и листьях) и карвакрола (с 6,4 до $4,9 \%$ в соцветиях и с 3,3 до 2,7\% в стеблях и листьях). Массовая доля лимонена увеличивается в соцветиях (с 0,6 до 1,2\%) и уменьшается в стеблях и листьях (с 5,4 до 4,4\%). Так как железистый аппарат растений рода Monarda представляет собой экзогенные образования (головчатые волоски и пельтатные железки) [5], то секреторные структуры менее подвержены нарушениям целостности, и, следовательно, эфирное масло лучше сохраняется, а его компоненты более устойчивы к окислительному воздействию воздуха.

В связи с тем, что активность ферментов, участвующих в биосинтезе терпеноидов, находится под контролем гормонального баланса и изменяется в онтогенезе [10], нами проведен сравнительный анализ масел второго и третьего годов жизни M. didyma. Отличия наблюдаются в содержании основных компонентов. К третьему году жизни в растениях увеличивается содержание тимола и пара-цимола, уменьшается содержание карвакрола и $\gamma$-терпинена.

Сопоставляя компонентный состав масел по органам растения (соцветия, стебли и листья, вся надземная часть), видим, что содержание тимола в стеблях и листьях несколько выше (на 1,3-9,0\%), чем в соцветиях, где отмечено более высокое содержание карвакрола (на 0,5-3,1\%) и терпинен-4-ола (на 0,2-0,6\%). В содержании остальных компонентов эфирного масла существенных отличий по органам растения не наблюдалось. Следовательно, в качестве сырья для получения эфирного масла M. didyma целесообразно использовать всю надземную часть растения.

\section{Список литературы}

1. McClintock E., Epling C. // Univ. California Publ. Bot., 1942. Vol. 20, N2. Pp. 147-194.

2. Scora R.W. // Univ. California Publ. Bot., 1967. Vol. 41. Pp. 1-71.

3. Интродукция лекарственных, пряноароматических и технических растений / под ред. В.С. Соколова, И.Н. Сациперовой. М. ; Л., 1965. С. 177-180.

4. Сизова Н.В., Мяделец М.А. Состав и биологическая активность эфирного масла Монарды двойчатой (Monarda didyma L.) // Сырье и упаковка. 2012. №10. С. 20-22.

5. Корчашкина Н.В. Биологические особенности роста и развития видов рода монарда (Monarda L.) в условиях нечерноземной зоны Российской Федерации : дис. ... канд. биол. наук. М., 2009. 149 с.

6. Вишневская О.Е., Шаварда А.Л., Соловьева А.Е., Зверева О.А. Исследование компонентного состава эфирного масла растений рода Monarda (Lamiaceae), культивируемых в условиях северо-западного региона // Аграрная Россия. 2006. №6. С. 60-62.

7. Опарин Р.В., Покровский Л.М., Высочина Г.И., Ткачев А.В. Исследование химического состава эфирного масла Monarda fistulosa L. и M. didyma L., культивируемых в условиях Западной Сибири // Химия растительного сырья. 2000. №3. С. 19-24.

8. Николаевский В.В., Еременко А.Е., Иванов И.К. Биологическая активность эфирных масел. М., 1987. 144 с.

9. Дрягин В.М. Монарда - новое овощное пряно-вкусовое растение. М., 1994. 99 с.

10. Дмитриева В.Л., Дмитриев Л.Б. Изучение состава эфирных масел эфиромасличных растений нечерноземной зоны России // Известия ТСХА. 2011. Вып. 3. С. 106-119.

11. ГОСТ 24027.2-80 Сырье лекарственное растительное. Методы определения влажности, содержания золы, экстрактивных и дубильных веществ, эфирного масла.

12. Ткачев А.В. Исследование летучих веществ растений. Новосибирск, 2008. 969 с.

13. Капелев И.Г. Методические рекомендации по возделыванию монарды. Ялта, 1982.16 с.

14. Работягов В.Д., Хлыпенко Л.А., Корсакова С.П. Эфирно-масличные растения семейства Яснотковые из коллекции Никитского ботанического сада // Физиолого-биохимические аспекты изучения лекарственных растений. Новосибирск, 1998. С. 54-55.

15. Работягов В.Д., Исиков В.П., Овчаренко Н.С., Лопотова О.В. Состав эфирного масла у Monarda fistulosa L., пораженной мучнисто-росяным грибом Golovinomyces biocellatus (Ehreb.) Gel. // Черноморский ботанический журнал. 2010. Т. 6, №3. С. 373-377.

16. Шаин С.С., Курапов П.Б., Маланкина Е.Л., Дмитриева В.Л. и др. Гормональная регуляция биопродуктивности в онтогенезе эфиромасличных растений: мята перечная, змееголовник молдавский, монарда двойчатая // Биотехнология. 2000. Вып. 1. С. 179-195. 


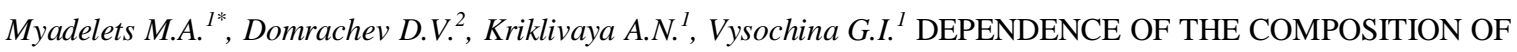
ESSENTIAL OIL OF MONARDA DIDYMA L. (LAMIACEAE) FROM THE AGE AND NATURE OF PLANT MATERIALS

${ }^{1}$ Central Siberian Botanical Garden, SB RAS, Zolotodolinskaya str., 101, Novosibirsk, 630090 (Russia),

e-mail: MarinaMyadelets@yandex.ru

${ }^{2}$ N.N. Vorozhtsov Novosibirsk Institute of Organic Chemistry, SB RAS, Lavrentjev ave., 9, Novosibirsk, 630090 (Russia)

The chemical composition of the essential oil from Monarda didyma L. (Lamiaceae), cultivated in the forest-steppe zone of Omsk Region has been studied by the method of chromato-mass-spectrometry. To obtain the essential oil, newly made and dried plant materials of the second and the third years of life have been used. Differences in the composition of the resulting oil are marked. Total detected more than 50 components, of which identified 37 compounds. The main components are thymol $(64,9 \%)$, methyl ether thymol $(7,6)$, para-cymene $(9,5), \gamma$-terpinene $(3,6)$, oct-1-en-3-ol $(2,9), \alpha$-terpinene $(2,3)$ and carvacrol $(1,2 \%)$.

Keywords: Monarda didyma L., essential oil, chromato-mass-spectrometry.

\section{References}

1. McClintock E., Epling C. Univ. California Publ. Bot., 1942, vol. 20, no. 2, pp. 147-194.

2. Scora R.W. Univ. California Publ. Bot., 1967, vol. 41, pp. 1-71.

3. Introduktsiia lekarstvennykh, prianoaromaticheskikh i tekhnicheskikh rastenii. Ed. V.S. Sokolov, I.N. Satsiperova. [Introduction of medicinal, industrial plants and pryanoaromaticheskih.]. Moscow; Leningrad, 1965, pp. 177-180. (in Russ.).

4. Sizova N.V., Miadelets M.A. Syr'e i upakovka, 2012, no. 10, pp. 20-22. (in Russ.).

5. Korchashkina N.V. Biologicheskie osobennosti rosta i razvitiia vidov roda monarda (Monarda L.) v usloviiakh nechernozemnoi zony Rossiiskoi Federatsii: dis. ... kand. biol. nauk. [Biological features of the growth and development of the genus Monarda (Monarda L.) under non-chernozem zone of the Russian Federation: the thesis is the candidate of biological sciences.]. Moscow, 2009, 149 p. (in Russ.).

6. Vishnevskaia O.E., Shavarda A.L., Solov'eva A.E., Zvereva O.A. Agrarnaia Rossiia, 2006, no. 6, pp. 60-62. (in Russ.).

7. Oparin R.V., Pokrovskii L.M., Vysochina G.I., Tkachev A.V. Khimiia rastitel'nogo syr'ia, 2000, no. 3, pp. 19-24. (in Russ.).

8. Nikolaevskii V.V., Eremenko A.E., Ivanov I.K. Biologicheskaia aktivnost' efirnykh masel. [Biological activity of essential oils.]. Moscow, 1987, 144 p. (in Russ.).

9. Driagin V.M. Monarda novoe ovoshchnoe priano-vkusovoe rastenie. [Monarda new vegetable spicy flavoring plant.]. Moscow, 1994, 99 p. (in Russ.).

10. Dmitrieva V.L., Dmitriev L.B. Izvestiia Timeriazevskoi sel'sko-khoziaistvennoi akademii, 2011, no. 3, pp. $106-119$. (in Russ.).

11. GOST 24027.2-80. Syr'e lekarstvennoe rastitel'noe. Metody opredeleniia vlazhnosti, soderzhaniia zoly, ekstraktivnykh i dubil'nykh veshchestv, efirnogo masla. [State Standard 24027.2-80. Raw medicinal plant. Methods for determination of moisture content, ash content, extractives and tannins, essential oil.]. (in Russ.).

12. Tkachev A.V. Issledovanie letuchikh veshchestv rastenii. [Исследование летучих веществ растений.]. 2008, 969 р. (in Russ.).

13. Kapelev I.G. Metodicheskie rekomendatsii po vozdelyvaniiu monardy. [Guidelines on cultivating Monarda.]. Yalta, $1982,16 \mathrm{p}$.

14. Rabotiagov V.D., Khlypenko L.A., Korsakova S.P. Fiziologo-biokhimicheskie aspekty izucheniia lekarstvennykh rastenii. [Metodicheskie rekomendatsii po vozdelyvaniiu monardy.]. Novosibirsk, 1998, pp. 54-55. (in Russ.).

15. Rabotiagov V.D., Isikov V.P., Ovcharenko N.S., Lopotova O.V. Chernomorskii botanicheskii zhurnal, 2010, vol. 6, no. 3, pp. 373-377. (in Russ.).

16. Shain S.S., Kurapov P.B., Malankina E.L., Dmitrieva V.L. Biotekhnologiia, 2000, no. 1, pp. 179-195. (in Russ.).

Received February 8, 2013

\footnotetext{
* Corresponding author.
} 

